\title{
Distribuição espacial das raízes de cafeeiro e dos poros de dois Latossolos sob manejo conservacionista
} \author{
Alisson L. da Costa $^{5} \&$ Larissa M. Oliveira ${ }^{6}$

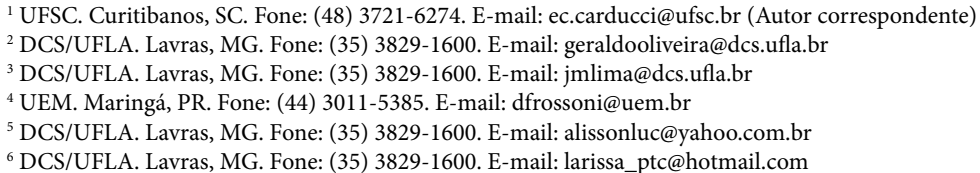

Carla E. Carducci ${ }^{1}$, Geraldo C. de Oliveira ${ }^{2}$, José M. Lima ${ }^{3}$, Diogo F. Rossoni ${ }^{4}$

\section{Palavras-chave:}

morfologia radicular

análise de imagem

tomografia computada de raios-X

krigagem

Coffea arabica L.

\begin{abstract}
R E S U M O
O objetivo deste trabalho foi avaliar o efeito do sistema de manejo que emprega práticas de conservação do solo na distribuição do sistema radicular de cafeeiros e na estrutura de dois Latossolos após seis anos de implantação da lavoura na região do Alto São Francisco, MG. Foram abertas três trincheiras aleatórias e longitudinais à linha de plantio $(0,70$ x 1,50 m) em um Latossolo gibbsítico e em um Latossolo caulinítico ambos sob sistema de manejo do solo que emprega práticas conservacionistas. A avaliação do sistema radicular foi feita pelo método do perfil cultural e análise digital de imagens $2 \mathrm{D}$, com posterior confecção de mapas de superfície das variáveis radiculares analisadas por meio da krigagem. Amostras de solo com estrutura preservada foram coletadas para quantificar a distribuição do diâmetro de poros 3D obtida por tomografia computada de raios-X. As raízes e poros foram classificados em: $1,>1$ e $\leq 3$ e $>3 \mathrm{~mm}$ de diâmetro. O sistema radicular dos cafeeiros de ambos os solos em estudo mesmo sobre o mesmo sistema de manejo apresentaram boa ramificação na direção horizontal e vertical. A maior concentração de raízes ocorreu na profundidade de 0,20-0,34 m no Latossolo caulinítico. No Latossolo gibbsítico, a distribuição radicular foi uniformizada especialmente na direção vertical do perfil do solo atingindo maiores profundidade. A maior ocorrência de raízes finas ocorreu no Latossolo gibsítico na profundidade de 0,80-0,94 m.
\end{abstract}

Key words: roots morphology image analyze X-ray CT scan kriging Coffea arabica $\mathrm{L}$.

\section{Spatial distribution of coffee roots and pores of two Latosols under conservationist management}

\begin{abstract}
A B S T R A C T
The aim of this study was to evaluate the effect of management system employing soil conservation practices in the coffee root system distribution and in the structure of two Latosols after six years in the crop establishment in Alto São Francisco Valley, MG. Three random trenches were made lengthwise along the row planting $(0.70 \times 1.50 \mathrm{~m})$ in a gibbsitic Latosol and a kaolinitc Latosol both under soil management system employing soil conservationist practices. The root system evaluation was done by crop profile methods and 2D image analyze, with subsequent surface mapping of the root variables analyzed by kriging. Intact soil cores were sampled for pore diameter distribution analysed by X-ray CT scan. The roots and pores were classified by diameter:1, $>1$ and $\leq 3$ and $>3 \mathrm{~mm}$. The coffee root system in both soils under study on the same management system showed good branching in horizontal and vertical direction. The highest root concentration occurred at $0.20-0.34 \mathrm{~m}$ depth in kaolinitic Latosol. In gibbsitic Latosol the root distribution was uniform, especially in the vertical soil profile reaching greater depths. The highest occurrence of fine roots in the gibbsitic Latosol occurred at 0.80-0.94 m depth.
\end{abstract}

\section{INTRODUÇÃO}

O desenvolvimento das plantas depende das interações entre os atributos do solo com o ambiente radicular. Na realidade, o crescimento das raízes depende da estrutura do solo, porém a estruturação do solo também depende das raízes, e descobrir o limiar onde o ambiente do solo controla a distribuição espacial das raízes e como o crescimento da raiz modifica a estrutura do solo, é trabalho bem complexo (Kaestner et al., 2006).

A crescente busca por conhecimento e reconhecimento do papel das interações solo-raiz na produtividade das culturas e seus efeitos ambientais, tem ganhado cada vez mais notoriedade. As interações entre o solo e a raiz são vistas como o elemento chave para a segunda revolução verde que tem, por finalidade, maximizar a produtividade (Lynch, 2007).

As raízes, além de serem responsáveis pela absorção de água e pela sustentação da planta, são parte essencial nos processos de formação e estabilização dos agregados do solo permitidos pelos mecanismos físicos e químicos gerados com seu desenvolvimento (Salton et al., 2008).

Como mecanismos físicos entende-se o agrupamento das partículas sólidas em razão de pressões exercidas durante o 
crescimento da raiz, e como mecanismos químicos aqueles que estimulam a cimentação das partículas, por meio de exsudados orgânicos produzidos por micro-organismos do solo provenientes da decomposição da matéria orgânica (Mairhofer et al., 2012; Costa Júnior et al., 2012) aliados às hifas dos fungos que agem na formação de estruturas mais diversificadas com incremento na porosidade (Martin et al., 2012).

Assim, o conhecimento sobre a distribuição do sistema radicular das plantas cultiváveis, nem como as prováveis alterações na estrutura do solo, constituem o resultado das interações entre os diferentes sistemas de manejo e as condições edafoclimáticas intrínsecas ao solo. Portanto, a busca por sistemas de manejo do solo que promovam o melhor desenvolvimento das raízes em profundidade possibilita, à cultura, resistir bem aos períodos de seca, o que tem merecido destaque na pesquisa (Raij, 2008).

Nesta linha de pensamento um sistema de manejo que agrega práticas conservacionistas do solo para o cultivo de cafeeiros está sendo utilizado por cafeicultores da região do Alto São Francisco, MG, e vem ganhando notoriedade por aliar melhorias físicas, hídricas e químicas do solo à elevação da produtividade e à busca da sustentabilidade ambiental (Serafim et al., 2013; Ramos et al., 2013).

Este sistema visa potencializar o desempenho radicular do cafeeiro por meio do uso eficiente da água e nutrientes distribuídos ao longo do perfil do solo; as práticas conservacionistas utilizadas são: as mecânicas - o preparo do solo a $0,60 \mathrm{~m}$ de profundidade, implantação de miniterraços pelo procedimento de arraste de terra mais resíduo vegetal da entrelinha ao pé da planta com $0,50 \mathrm{~m}$ de altura, os tratos culturais são feitos via tração animal para minimizar a compressão superficial; a prática vegetativa - manutenção de Brachiaria sp. na entrelinha dos cafeeiros que propicia o acúmulo de resíduos vegetais, o que eleva o conteúdo de matéria orgânica do solo e, como prática edáfica, além da correção e adubação em maior profundidade $(0,40 \mathrm{~m})$ há a aplicação de gesso agrícola $\left(7 \mathrm{~kg} \mathrm{~m}^{-1}\right)$ sobre a superfície do solo na linha de plantio (Serafim et al., 2013).

Análises visuais vêm indicando excelente desenvolvimento radicular dos cafeeiros submetidos a este sistema de manejo; entretanto, é preciso quantificar esses resultados, o que é possível com o processamento digital de imagens $2 \mathrm{D}$ e $3 \mathrm{D}$, que se destacam como uma das linhas de pesquisa mais promissoras especialmente no que se refere aos efeitos dos sistemas de manejo no ambiente.

Com a análise de imagens eliminam-se as subjetividades encontradas nos métodos clássicos, além do maior poder de predição, essencial em estudos do sistema radicular e da estrutura do solo o que se deve, além da maior resolução espacial, à praticidade em quantificar grandezas de maior relevância (Jorge \& Silva, 2010; Mairhofer et al., 2012).

Portanto, realizou-se este trabalho com o objetivo de avaliar o efeito do sistema de manejo que emprega práticas de conservação do solo na distribuição do sistema radicular de cafeeiros e na estrutura de dois Latossolos após seis anos de implantação da lavoura na região do Alto São Francisco, MG.

\section{Material e Métodos}

O estudo foi realizado em solos sob lavoura cafeeiro localizadas no município de São Roque de Minas, região fisiográfica do Alto São Francisco, MG. Com área de 52 ha e tendo, por coordenadas, $20^{\circ} 11^{\prime} 31^{\prime \prime} \mathrm{S}$ e $46^{\circ} 22^{\prime} 07^{\prime \prime}$ com altitude de $826 \mathrm{~m}$. O clima da região é do tipo Cwa, segundo classificação de Köppen, com precipitação pluvial média anual de $1.344 \mathrm{~mm}$ e estação seca bem definida nos meses de maio a setembro (Menegasse et al., 2002).

Os solos em estudo foram descrito de acordo com Santos et al. (2013) e classificado segundo Embrapa (2013), como Latossolo Vermelho Distrófico típico (LVd) e Latossolo Vermelho Amarelo Distrófico cambissólico (LVAd). De acordo com Carducci et al. (2013) a mineralogia dos solos em estudo é gibbsítica para o LVd e caulinítica para o LVAd.

O sistema em estudo vem sendo conduzido de acordo com as premissas de um sistema de manejo do solo que emprega práticas conservacionistas do solo e da água (Serafim et al., 2013) e que vem sendo utilizado na região há aproximadamente 12 anos.

A lavoura é composta pela cultivar Catucaí Amarelo Multilínea (Coffea arabica L.) cultivada em plantio semiadensado (0,65 x 2,50 m); no preparo do solo foram empregadas em área total uma aração e duas gradagens seguidas da aplicação de calcário dolomítico $\left(4 \mathrm{Mg} \mathrm{ha}^{-1}\right)$ e gesso agrícola $\left(1,92 \mathrm{Mg} \mathrm{ha}^{-1}\right)$ incorporados até $0,20 \mathrm{~m}$ de profundidade.

Após a correção do solo em área total foram abertos os sulcos de plantio a $0,60 \mathrm{~m}$ de profundidade e $0,50 \mathrm{~m}$ de largura, com uso de equipamento que permite, além da abertura em maior profundidade, o revolvimento do solo e a aplicação de corretivos e fertilizantes de forma homogênea até a profundidade de 0,40 $\mathrm{m}$ (Ticianel, 2013). No sulco foram aplicados $8 \mathrm{Mg} \mathrm{ha}^{-1}(2 \mathrm{~kg}$ $\mathrm{m}^{-1}$ ) de calcário dolomítico e a adubação de base (formulado 08-44-00, enriquecido com 1,5\% $\mathrm{Zn}$ e $0,5 \% \mathrm{~B}$ ); as mudas do cafeeiro foram plantadas entre a segunda quinzena de outubro e a primeira quinzena de novembro/2005.

Cerca de três meses após o plantio, o gesso foi distribuído na superfície do solo e ao longo da linha de cultivo, sendo este material recoberto com material de solo misturado com material vegetal proveniente da entre linha ("chegada de terra" junto ao tronco do cafeeiro).

Em conjunto com a instalação da lavoura foi implantada, como cultura de cobertura, a Brachiaria decumbens (Syn. Urochloa) nas entrelinhas sendo esta cortada periodicamente por meio de roçadora que faz com que o resíduo vegetal produzido seja direcionado para a linha de cultivo. Os tratos culturais da lavoura foram realizados com equipamento de tração animal; no entanto, a colheita é mecanizada. O monitoramento do estado nutricional das plantas e o manejo das adubações são feitos com base em análise foliar realizada no período de dezembro a abril (Serafim et al., 2013).

Nas áreas de estudos foram abertas trincheiras para a descrição morfológica e à coleta de amostras de solo com estrutura preservada em aneis volumétricos $(0,065 \mathrm{~m}$ diâmetro 
e 0,025 m altura) e deformada para caracterização física e química na linha de plantio, logo abaixo da camada de gesso, nas profundidades de 0,20-0,34; 0,80-0,94 e 1,50-1,64 m.

As análises granulométricas foram realizadas pelo emprego de agitação lenta da suspensão do solo, contendo $\mathrm{NaOH} 1 \mathrm{~N}$ durante 16 h (EMBRAPA, 2011).

As amostras com estrutura preservada foram devidamente preparadas e saturadas por meio da elevação gradual de uma lâmina de água e encaminhadas ao funil de Buchner. Após atingirem o equilíbrio hídrico no potencial matricial de $-6 \mathrm{kPa}$, considerada a capacidade de campo para Latossolos, estas foram pesadas e determinada a resistência do solo a penetração (RP), utilizando-se o penetrógrafo eletrônico de bancada, conforme Lima et al. (2012). Após determinação da RP as amostras foram secas em estufa a $105-110^{\circ} \mathrm{C}$, por $24 \mathrm{~h}$, para determinação da densidade do solo (Ds) (EMBRAPA, 2011) (Tabela 1).

$\mathrm{Na}$ época das avaliações de campo (setembro/2011) os cafeeiros estavam com idade fisiológica de aproximadamente seis anos e, portanto, em completo desenvolvimento do sistema radicular (Rena \& Guimarães, 2000).

Para a avaliação do sistema radicular foi utilizado o método da trincheira pelo estudo do perfil cultural (Brasil et al., 2007). Foram abertas três trincheiras aleatórias e longitudinais à linha de cultivo do cafeeiro com dimensões de $0,70 \mathrm{~m}$ de largura $\mathrm{x}$ $1,50 \mathrm{~m}$ de comprimento x 1,50 m de profundidade para cada solo avaliado. A parede vertical da trincheira sob a projeção da saia do cafeeiro e a $10 \mathrm{~cm}$ de distância do tronco da planta foi utilizada para avaliação das raízes, o solo ao longo da parede da trincheira foi escarificado, ou seja, foi removida uma fina camada de solo $(\cong 3 \mathrm{~cm})$ para exposição das raízes.

Após este procedimento e para elevar o contraste de cores entre o solo e as raízes, estas receberam uma fina camada de tinta branca; posteriormente, um gride de metal com as mesmas dimensões da trincheira ( $0,70 \mathrm{~m}$ largura $\mathrm{x} 1,50 \mathrm{~m}$ comprimento) foi colocado em perfeito contato com a parede da trincheira $e$ sobre as raízes (Figura 1A e 1B) para aquisição das imagens digitais. O gride foi constituído por quadrículas com dimensão de $5 \times 5 \mathrm{~cm}$, totalizando 420 pontos de amostragem.

A aquisição das imagens digitais foi efetuada com máquina digital semiprofissional com resolução espacial de sete megapixels. Após a aquisição as imagens foram corrigidas e alinhadas com o uso do software Adobe Photoshop CS5 12.0.4; em seguida foram submetidas à quantificação das seguintes variáveis radiculares: área superficial $\left(\mathrm{mm}^{2}\right)$, comprimento $(\mathrm{mm})$, volume $\left(\mathrm{mm}^{3}\right)$ e número de raízes obtidas em diferentes diâmetros identificados pelo aplicativo Safira (Jorge \& Silva, 2010). Para execução das análises tomográficas que visam ao maior detalhamento da distribuição do diâmetro de poros do solo em três dimensões (3D), foram coletadas, nas mesmas trincheiras citadas anteriormente após a avaliação das raízes, amostras de solo com estrutura preservada em cilindros de acrílico (0,006 $\mathrm{m}$ diâmetro x 0,14 $\mathrm{m}$ altura), entre plantas e na linha de plantio logo abaixo da camada de gesso, nas profundidades de $0,20-0,34 ; 0,80-0,94$ e $1,50-1,64 \mathrm{~m}$ em

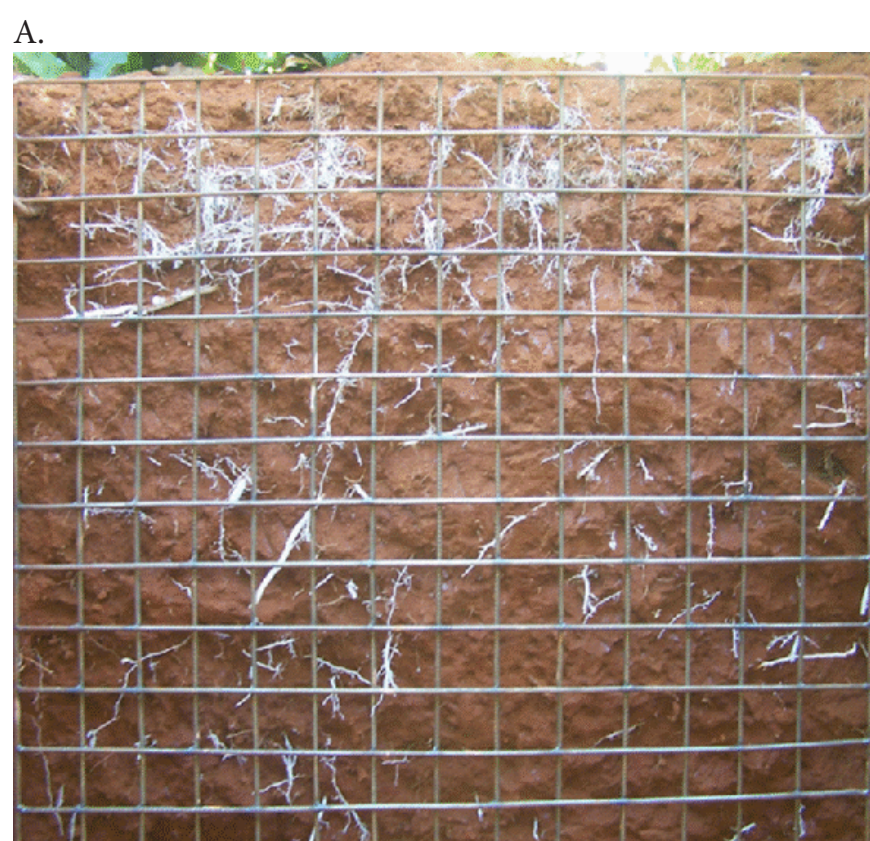

B.

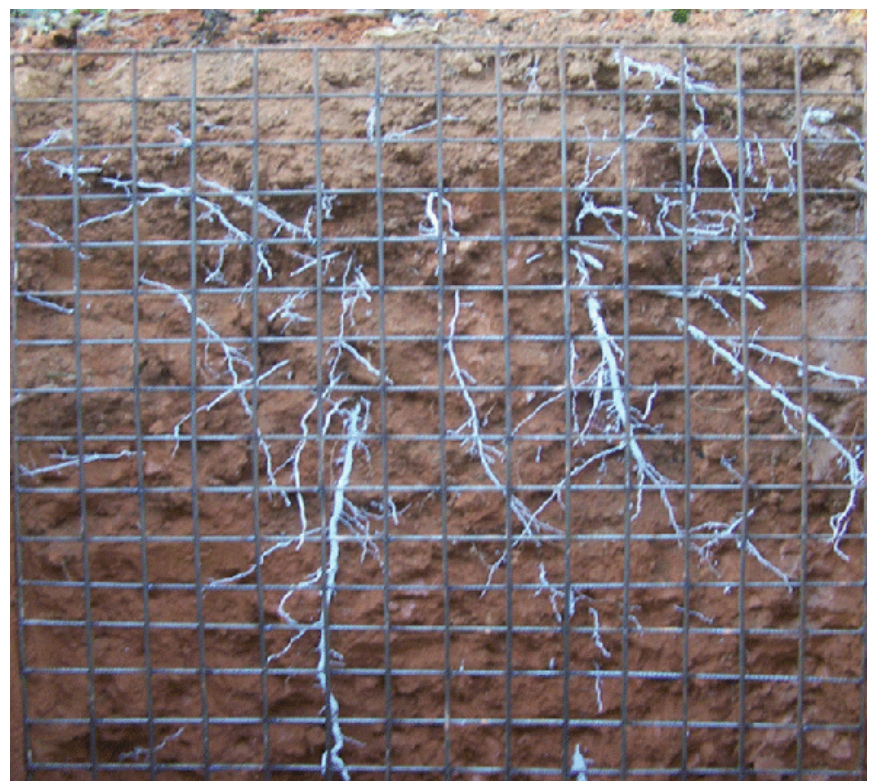

Figura 1. Representação esquemática do gride de mapeamento até o centro da trincheira. Latossolo gibbsítico (A), Latossolo caulinítico (B)

três repetições. Para este tipo de coleta para o qual visou ao mínimo de perturbação à estrutura do solo, foi utilizada uma ponteira de aço para encaixe do cilindro de acrílico. Essas profundidades foram selecionadas com base na análise visual do perfil do solo que identificou diferenças marcantes entre as mesmas.

As amostras de solo em cilindros de acrílico foram secas a $40{ }^{\circ} \mathrm{C}$ em estufa de circulação forçada para minimizar possíveis interferências dos filmes de água na atenuação dos raios-X. Para a geração das imagens foram escaneados 0,0033 $\mathrm{m}$ de cada amostra exatamente no centro, em um tomógrafo EVS/GE MS8X-130 (tubo de raios-X de tungstênio $130 \mathrm{kV}$ e $200 \mathrm{~mA}$ ) de terceira geração pré-clínico, com feixe em cone mantido no Laboratório de Imagem de Solo da Universidade 
de Guelph, Canadá. A energia de excitação de 120 kV e 170 $\mathrm{mA}$ foi empregada nas amostras gerando uma sequência axial de imagens com 16-bit de resolução radiométrica com tempo de exposição de 3500 Ms. Para redução dos artefatos provenientes dos feixes de raios-X policromátricos foram pré-filtrados utilizando-se uma película de cobre $(0,5 \mathrm{~mm}$ de espessura).

A partir das projeções axiais $2 \mathrm{D}$ resultantes do escaneamento a $20 \mu \mathrm{m}$ de resolução espacial, subvolumes de interesse foram selecionados exatamente no centro da imagem e reconstruídos a $60 \mu \mathrm{m}$ de resolução espacial (666 voxel x 666 voxel x 550 fatias) com tamanho do arquivo de $500 \mathrm{MB}$ por meio do aplicativo "eXplore Reconstruction Utility (GE Healthcare, 2006).

Com a finalidade de comparar a atenuação de raios-X, em imagens tomográficas, foram utilizados os valores em Unidade Hounsfield (são definidos em relação ao ar [-1000 UH] e a água $[0 \mathrm{UH}]$ ). Subsequentemente, os coeficientes da água e do ar foram calculados e um filtro de suavização gaussiano (raio de 1 voxel) foi utilizado para reduzir o ruído e os artefatos da imagem com o auxílio do MicroView (GE Healthcare, 2006), antecedendo aos cálculos dos poros no aplicativo NIH ImageJ (Rasband, 2002).

Os procedimentos de binarização ou threshold foram feitos no NIH ImageJ com base no trabalho de Schlüter et al. (2010) que empregaram o reconhecimento das bordas dos poros pelo método Laplaciano detectados na "imagem semente" (seededregion-growing) para atribuir, aos voxels associados, o valor "zero". Para tanto foi necessário fixar os valores da escala de cinza na imagem (utilizaram-se as posições dos picos de ar e sólidos do histograma de cada imagem), para maximizar as diferenças entre os limites entre os poros e os não poros (fase sólida).

Com o NIH Image (Rasband, 2002) todas as análises foram feitas nas imagens 3D, o que permitiu diferenciar os dados de acordo com as classes de diâmetro de poros pretendidos. Para isto foi utilizada a função "Analyze Particle" que permitiu calcular as dimensões dos poros (número, volume e área). Esta função detecta e mede cada poro presente no volume total da imagem binária 3D. A partir do resultado foi calculado o diâmetro do poro equivalente a uma esfera (simulação geométrica espacial).

As raízes quantificadas na análise das imagens $2 \mathrm{D}$ foram distribuídas em três classes de diâmetros: 1 - raízes finas ou absorventes $(1 \mathrm{~mm}), 2$ - raízes médias ou suporte das absorventes ( $>1 \mathrm{e} \leq 3 \mathrm{~mm}$ ), 3 - raízes grossas ou permanentes $(>3 \mathrm{~mm}$ ) (Rena \& Guimarães, 2000; Motta et al., 2006). Concomitantemente, procedeu-se à classificação dos poros detectáveis com diâmetro superior a um milímetro, correspondentes aos macroporos e distribuídos nas mesmas classes de diâmetro das raízes.

As inferências estatísticas foram feitas em nível de 5\% de probabilidade. As análises e os gráficos classificatórios foram obtidos por meio de funções em linguagem $\mathrm{R}$ ( $\mathrm{R}$ Development Core Team, 2012) assim como o teste de correlação de Pearson entre as variáveis do sistema radicular e porosidade.

De posse dos resultados obtidos em cada unidade de amostragem do gride $(0,70 \mathrm{~m} \times 1,50 \mathrm{~m}$ subdivididos em quadrículas de $0,05 \times 0,05 \mathrm{~m}$, totalizando 420 pontos) foram estimados valores para os locais não amostrados com condições de não tendenciosidade e variância mínima. Para a krigagem utilizou-se o centroide de cada unidade amostral do gride para geração dos mapas de superfície com auxílio do pacote geoR (Ribeiro Júnior \& Diggle, 2001), a fim de buscar melhor visualização da distribuição das variáveis radiculares no perfil do solo.

\section{Resultados e Discussão}

Os solos em estudo apesentam textura muito argilosa e os valores de densidade do solo (Ds) e resistência do solo a penetração (RP) obtidos nas profundidades abaixo de $0,80 \mathrm{~m}$ (Tabela 1) refletem tanto a granulometria quanto a mineralogia dos mesmos (Ferreira et al., 1999) (Tabela 1). No entanto, na profundidade de $0,20-0,34 \mathrm{~m}$ os valores menores de Ds e $\mathrm{RP}$ resultam do revolvimento que os mesmos sofreram por ocasião do preparo, o que foi fundamental para o melhor desenvolvimento inicial dos cafeeiros.

A variabilidade da rede radicular nos dois solos avaliados foi distinta (Figura 2) corroborando com Franco \& Inforzato (1946) que descreveram a inexistência de um sistema radicular típico do cafeeiro, e sim uma conformação diferente do sistema radicular para cada classe de solo estudada.

O sistema radicular dos cafeeiros atingiu, aos seis anos de idade, a profundidade de $1,50 \mathrm{~m}$, o que representa boa distribuição espacial e que pode ter sido favorecido pelos baixos valores de Ds e RP de ambos os solos (Tabela 1). Isto foi observado principalmente para o Latossolo gibbsítico que apresentou melhor ramificação do sistema radicular ao longo do perfil (6,40\% de raízes finas, $85,29 \%$ de raízes médias e $8,31 \%$ de raízes grossas) em relação ao Latossolo caulinítico (70,50\% de raízes médias, 29,29\% de raízes grossas).

Tabela 1. Granulometria, densidade do solo e resistência a penetração do Latossolo gibbsítico (LVd) e um Latossolo caulinítico (LVAd) sob o sistema de manejo e estudo em diferentes profundidades

\begin{tabular}{|c|c|c|c|c|c|c|c|c|c|c|}
\hline \multirow{2}{*}{$\begin{array}{l}\text { Prof. }^{1} \\
\text { (cm) }\end{array}$} & \multicolumn{5}{|c|}{ LVd } & \multicolumn{5}{|c|}{ LVAd } \\
\hline & Argila & Silte & Areia & $\begin{array}{c}\mathrm{Ds}^{2} \\
\mathrm{~kg} \mathrm{dm}^{-3}\end{array}$ & $\begin{array}{l}\mathbf{R P}^{3} \\
\text { Mpa }\end{array}$ & Argila & Silte & Areia & $\begin{array}{c}\mathrm{Ds}^{2} \\
\mathrm{~kg} \mathrm{dm}^{-3}\end{array}$ & $\begin{array}{l}\mathrm{RP}^{3} \\
\mathrm{MPa}\end{array}$ \\
\hline $0,20-0,34$ & 869 & 66 & 65 & 0,95 & 0,19 & 716 & 210 & 74 & 0,94 & 0,33 \\
\hline $1,50-1,64$ & 904 & 39 & 57 & 1,04 & 0,13 & 700 & 238 & 62 & 1,18 & 0,52 \\
\hline
\end{tabular}

${ }_{1}$ Prof - Profundidade do solo. ${ }^{2} \mathrm{Ds}$ - Densidade global do solo. ${ }^{3 \mathrm{RP}}$ - Resistência do solo a penetração determinada em amostras com potencial matricial de $-6 \mathrm{kPa}$. considerada a capacidade de campo para Latossolos 

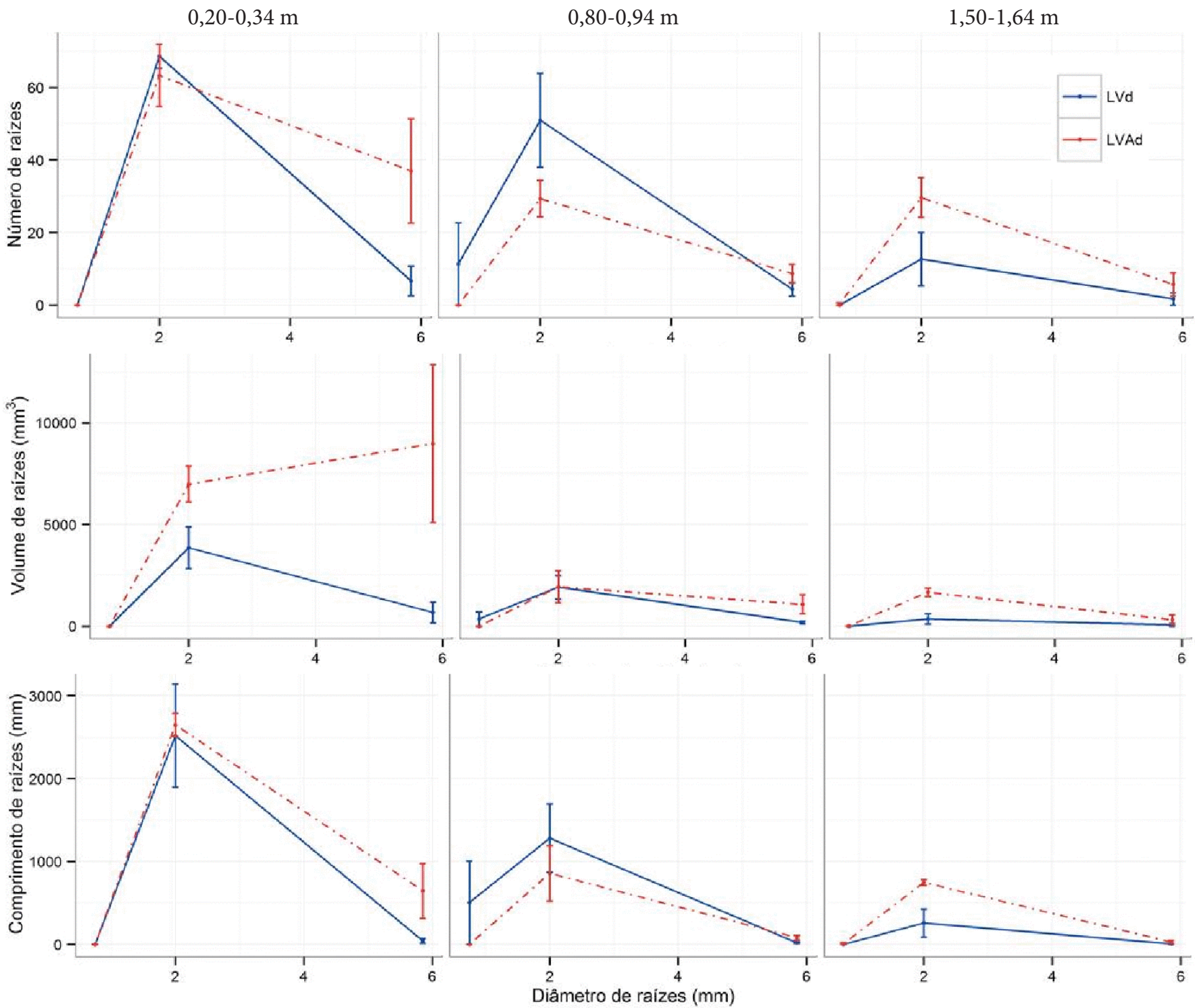

As classes de diâmetro $(1 ;>1 \mathrm{e} \leq 3 ;>3 \mathrm{~mm})$ estão representadas pelos valores médios. As barras correspondem ao erro padrão da média

Figura 2. Distribuição do sistema radicular do cafeeiro (número, comprimento - $\mathrm{mm}$ e volume - $\mathrm{mm}^{3}$ das raízes) nas profundidades de 0,20-0,34; 0,80-0,94 e 1,50-1,64 m para o Latossolo gibbsítico (LVd) e Latossolo caulinítico (LVAd)

Esses resultados confirmam a influência das condições do ambiente aos quais os cafeeiros estão inseridos. Fato este relacionado com as interações entre os diferentes fatores (sistema de manejo, solo e planta) que podem interferir no desenvolvimento radicular o que só, foi possível detectar por meio da análise de imagens digitais (Figura 2). Este procedimento apresenta maior poder de predição em relação aos métodos de avaliação clássicos, por eliminar a subjetividade na aquisição dos dados (Jorge \& Silva, 2010).

$\mathrm{Na}$ profundidade de $0,20-0,34 \mathrm{~m}$ não foram detectadas raízes finas $(1 \mathrm{~mm})$ nos solos avaliados, embora tenham sido observadas diferenças marcantes em comprimento e principalmente em número de raízes nas demais classes. As raízes médias predominaram no Latossolo gibbsítico (91,15\%) em relação ao caulinítico $(63,13 \%)$, ao contrário das raízes grossas que ocorreram em maior frequência no Latossolo caulinítico $(36,87 \%)$ em comparação ao gibbsítico $(8,85 \%)$.
Independentemente da classificação na profundidade superficial foi observado um volume maior de raízes no Latossolo caulinítico (Figura 2), o que evidencia o efeito positivo do intenso revolvimento do solo, realizado no momento do preparo da linha de cultivo. Para este solo a quebra de agregados nos primeiros $0,40 \mathrm{~m}$ pode ter sido benéfica por proporcionar sua homogeneização e, em contrapartida a dos poros (Schaffrath et al., 2008), com consequência no desenvolvimento das raízes. O Latossolo caulinítico apresenta, em condições naturais, estrutura em blocos dotados, portanto, de maior adensamento em relação ao Latossolo gibbsítico (Ferreira et al., 1999).

O revolvimento superficial no Latossolo gibbsítico, não parece ter proporcionado os mesmos benefícios no enraizamento do cafeeiro. Pelo contrário, por ocasião do preparo a quebra de agregados originalmente frágeis, pode ter condicionado prejuízos por aumentar demasiadamente o volume de poros grandes (Figura 3) com consequências 

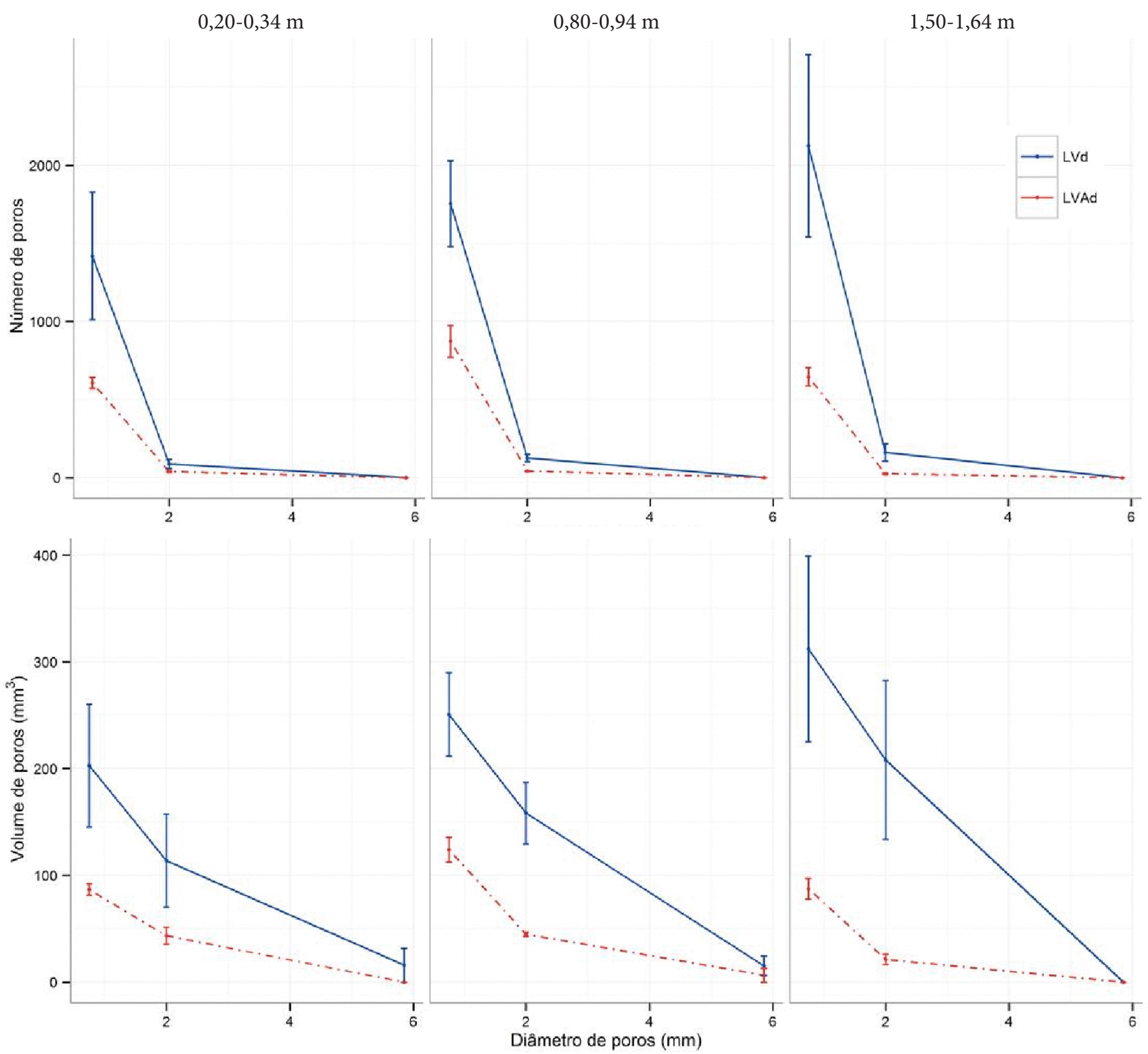

As classes de diâmetro $(1 ;>1 \mathrm{e} \leq 3 ;>3 \mathrm{~mm})$ estão representadas pelos valores médios. As barras correspondem ao erro padrão da média

Figura 3. Distribuição do diâmetro de poros (número e volume - $\mathrm{mm}^{3}$ ) nas profundidades de $0,20-0,34 ; 0,80-0,94$

e 1,50-1,64 m para o Latossolo gibbsítico (LVd) e Latossolo caulinítico (LVAd)

negativas no ambiente radicular, a exemplo do ressecamento muito rápido na superfície (Carducci et al., 2013).

$\mathrm{Na}$ profundidade de 0,80-0,94 $\mathrm{m}$ o sistema radicular dos cafeeiros apresentou tendência de similaridade na sua conformação; concomitantemente a redução no volume radicular em ambos os solos, fato este característico da espécie (Rena \& Guimãraes, 2000). No entanto, o número e o comprimento de raízes finas (15\%) e médias (78\%) encontrados no Latossolo gibbsitíco superaram o caulinítico que apresentou maior proporção de raízes grossas e curtas $(22,81 \%)$ (Figura 2).

Ainda nesta maior profundidade se observaram semelhanças em relação ao volume de raízes as quais ocupam os espaços vazios do solo (Figura 2 e 3). As raízes grossas são responsáveis pela sustentação da planta enquanto as raízes finas e médias são mais eficientes na aquisição dos recursos edáficos (Jesus et al., 2006).

Algumas diferenças na distribuição das raízes em profundidades ainda maiores (1,50-1,64 m) foram detectadas pela análise de imagem 2D. Nesta profundidade o volume de raízes médias e grossas do cafeeiro no Latossolo caulinítico foi superior ao gibbsítico (Figura 1).

Esta grande variação na frequência dentro das classes de raízes pode ser atribuída às adversidades do ambiente a que estas plantas foram expostas (Motta et al., 2006), pois o desenvolvimento diferenciado das raízes se deve às modificações implementadas pelo sistema de manejo, com particularidades em cada solo. 
É notório que o comprimento e a área superficial das raízes estão intimamente associados às suas características em relação à absorção de nutrientes (Jesus et al., 2006) e, desta forma, o maior crescimento das raízes verificado pelo comprimento radicular é um indicador de maior exploração do solo para a aquisição dos recursos edáficos; mesmo assim, este fato depende de uma ampla gama de atributos do solo, a exemplo da distribuição do diâmetro dos poros (Mairhofer et al., 2012; Martin et al., 2012). Embora se destaque que uma grande parte do sistema radicular das plantas é formada por raízes finas e muito finas $(\varnothing<1 \mathrm{~mm})$ com alta eficiência na absorção de água e aquisição de nutrientes, devido à elevada permeabilidade da membrana (Jesus et al., 2006) sabe-se que as mesmas apresentam o ciclo vital muito rápido (morte e regeneração), em busca do equilíbrio com a parte aérea (Motta et al., 2006).

Neste estudo mencionadas raízes foram primeiro subestimadas às características particulares dessa fração radicular, associadas às limitações da técnica no momento da escarificação do perfil e à sobreposição das raízes no momento da aquisição da imagem digital feita em campo. Para detectar estruturas com tais dimensões, técnicas com maior resolução são necessárias, a exemplo dos métodos não invasivos para visualização e quantificação das raízes em 3D (Kaestner et al., 2006; Mairhofer et al., 2012).

Apesar de ser um método não destrutivo, a análise de imagens 3D por meio da tomografia computada de raios-X apresenta certa complexidade em se atribuir com exatidão o limiar entre os diferentes componentes estruturais do solo, tais como o conteúdo de água (fase líquida), as partículas minerais e orgânicas (fase sólida) e o espaço poroso (fase gasosa).

Aplicar a limiarização em uma imagem para identificar a fase orgânica e a fase sólida, é complexo. As bordas das partículas sólidas, a exemplo do quartzo, apresentam o mesmo nível na escala de cinza, ou seja, mesmo valor de atenuação dos raios-X das raízes e da matéria orgânica (Kaestner et al., 2006; Mairhofer et al., 2012).

Em outras palavras, um grande volume de poros encontrados em ambos os solos, podem ser de raízes vivas ou em decomposição, que só posteriormente originarão os bioporos (Lima et al., 2012). A limiarização utilizada permitiu separar somente os poros (fase gasosa) dos não poros (fase sólida). Ressalta-se que no momento da amostragem do solo havia, visualmente, uma grande quantidade de raízes com diferentes diâmetros distribuídas ao longo do perfil do solo.

Ao longo do perfil destacou-se a superioridade em volume dos poros menores $(\varnothing<2 \mathrm{~mm})$ do Latossolo gibbsítico em relação ao caulinítico, tal como uma ligeira semelhança dos poros maiores $(\varnothing>2 \mathrm{~mm}$ ) entre ambos os solos, obtidos por meio da técnica tomográfica (Figura 3 ).

Na literatura é ressaltado que a mineralogia da fração argila desempenha importante papel na formação dos agregados do solo e, consequentemente, no espaço poroso entre eles (Ferreira et al., 1999). No caso do Latossolo gibbsítico em estudo a formação da estrutura do tipo granular forte, com grande proporção de microagregados de gênese complexa (Ferreira et al., 1999), é a responsável pela existência de uma extensa rede de poros (Figura 3 ) organizados em cavidades interconectadas típico desta ordem de solos (Vidal-Torrado et al., 1999).

Não obstante, no Latossolo caulinítico, que apresenta estrutura em blocos, função da caulinita na fração argila, não há uma organização microestrutural (Ferreira et al., 1999), o que foi refletido na menor frequência dos poros de maiores diâmetros ao longo do perfil avaliado (Figura 3). Apesar disto, por terem sido submetidos ao mesmo tipo de manejo, além da mineralogia, os fatores bióticos e mecânicos possivelmente influenciaram na distribuição dos poros em razão da forte interação que existe entre solo-raiz refletindo nas alterações estruturais (Martin et al., 2012; Costa Júnior et al., 2012).

Esta afirmação é justificada pela correlação positiva e significativa $\left(r=0,99^{* *}\right)$ entre as raízes médias e poros maiores $(\varnothing>2 \mathrm{~mm})$ no Latossolo caulinítico a $0,20-0,34 \mathrm{~m}$ de profundidade e pela correlação positiva e significativa $(r=$ $0,99^{\star}$ ) ao longo do perfil do Latossolo gibbsítico entre as raízes finas e os poros menores $(\varnothing<2 \mathrm{~mm})$ e correlação negativa e significativa entre as raízes médias e grossas com poros menores $\left(\mathrm{r}=-0,99^{\star}\right.$ e $\mathrm{r}=-1^{\star * \star}$, respectivamente). As raízes dos cafeeiros podem contribuir com a formação de agregados maiores seja pelo seu crecimento e/ou pela atividade dos micro-organismos devido à liberação de exsudados orgânicos, crecimento e morte de tecido (Salton et al., 2008). Isto pode ter promovido a uniformização na hierarquia do diâmetro de poros (Martin et al., 2012) como observado no Latossolo caulinítico. Embora algumas distinções no que se refere ao volume de solo ocupado por poros, tenham sido detectadas em ambos os solos, o que ressalta no caracter mineralógico (Ferreira et al., 1999).

Esta conformação estrutural adquirida detectada por meio da distribuição dos poros em 3D foi promovida pela interação entre o fator mineralógico e o biótico (sistema de manejo, planta e organismos) que incrementou o espaço poroso responsável pelo desenvolvimento das raízes e da biota do solo, além dos efeitos benéficos no fluxo de ar e água (Salton et al., 2008; Lima et al., 2012).

Para melhor visualizar a interação existente entre a estrutura do solo e o desenvolvimento das raízes ao longo do perfil influenciado pelo sistema de manejo em estudo, bem como definir o grau de dependência das variáveis avaliadas e seu domínio no espaço, utilizaram-se os mapas de superfície obtidos pela técnica da krigagem (Figura 4).

Pela gradação dos tons das cores nota-se a grande variabilidade das variáveis estudadas ao longo do perfil dos solos (gride $=0,70 \mathrm{~m}$ largura $\times 1,50 \mathrm{~m}$ de profundidade). Os mapas da distribuição espacial do volume, área superficial e comprimento das raízes apresentam diferenças marcantes na localização dos maiores e menores valores dessas variáveis, o que é característico do sistema radicular do cafeeiro (Rena \& Guimarães, 2000).

A maior concentração das variáveis radiculares no Latossolo caulinítico ocorreu exatamente na profundidade de 0,20-0,34 m, devido ao revolvimento. O preparo do solo possibilitou o alívio estrutural condicionando o aumento da porosidade (Schaffrath 


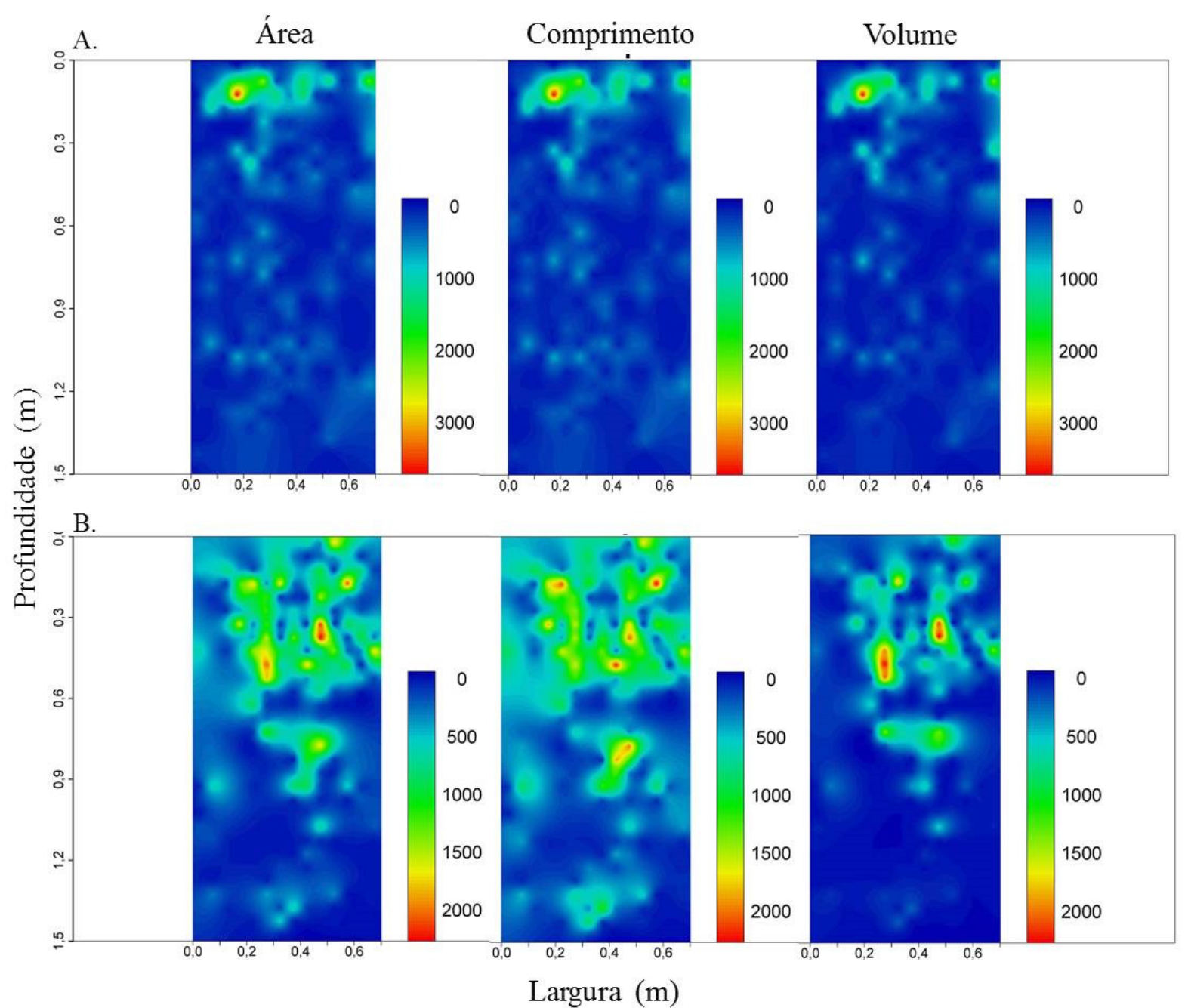

Figura 4. Mapas de distribuição espacial do sistema radicular do cafeeiro (volume - $\mathrm{mm}^{3}$, área de superfície - $\mathrm{mm}^{2} \mathrm{e}$ comprimento - mm) no sistema de manejo em estudo. A. Latossolo gibbsítico (LVd); B. Latossolo caulinítico (LVAd)

et al., 2008) e condições para o bom desenvolvimento horizontal e vertical das raízes (Figura 2, 3 e $4 \mathrm{~A}$ e B).

Por outro lado, a melhor distribuição espacial do sistema radicular do cafeeiro ocorreu no Latossolo gibbsítico (tons azuis no mapa), com maior volume, área superficial $(\approx 500$ $\mathrm{mm}^{3}$ ) e comprimento de raiz maior que $100 \mathrm{~mm}$ (Figura $4 \mathrm{~A}$ ). Salienta-se que este fato é de suma relevância por favorecer a aquisição de nutrientes e absorção de água em maior extensão do solo (Lynch, 2007) além de aeração adequada promovida pela maior proporção de poros com diferentes diâmetros (Figura 3).

Ficou evidente que a variabilidade espacial do sistema radicular é regida por fatores complexos que vão desde aqueles internos à planta, que estão ligados à expressão gênica, até os fatores externos, tais como a classe de solo, o sistema de manejo e a localização da água no solo, além do local de aplicação dos insumos agrícolas (Motta et al., 2006).

É importante destacar isto, pois compreender a espacialização radicular permite alcançar o aproveitamento máximo dos recursos edáficos disponíveis para as culturas (Franco \& Inforzato, 1946; Lima et al., 2012). Entretanto, esses processos ocorrem de forma simultânea e podem provocar grandes modificações na distribuição do espaço poroso, como confirmado por diferentes autores (Franco \& Inforzato, 1946; Inforzato \& Reis, 1963; Motta et al., 2006).

\section{Conclusões}

1. O sistema radicular dos cafeeiros de ambos os solos em estudo, mesmo sobre o mesmo sistema de manejo, apresentou boa ramificação na direção horizontal e vertical.

2. A maior concentração de raízes ocorreu na profundidade de 0,20-0,34 m no Latossolo caulinítico.

3. No Latossolo gibbsítico a distribuição radicular foi uniformizada, especialmente na direção vertical do perfil do solo atingindo maiores profundidades.

4. A maior ocorrência de raízes finas ocorreu no Latossolo gibsítico na profundidade de 0,80-0,94 m.

\section{Agradecimentos}

À FAPEMIG, pelo financiamento da pesquisa; ao Consórcio Embrapa Café, pelo empréstimo de veículos; ao CNPq, pela 
concessão da bolsa de estudos; à UFLA, pelo apoio institucional; à Empresa AP pelo apoio técnico e logístico e ao Dr. Richard J. Heck (University of Guelph - Canadá) pela permissão de uso dos laboratórios e auxílio na análise tomográfica.

\section{Literatura Citada}

Brasil, F. C.; Zonta, E.; Oliveira, M. R. G. Métodos de amostragem e quantificação para estudos do sistema radicular em condições de campo - Uma revisão crítica. Revista Ciência da Vida, v.27, p.14-33, 2007.

Carducci, C. E.; Oliveira, G. C.; Zeviani, W. M.; Lima, V. M. P.; Serafim, M. E. Bimodal pore distribution on soils under conservation management system for coffee crop. Engenharia Agrícola, v.33, p.291-302, 2013.

Costa Júnior, C.; Píccolo, M. C.; Siqueira Neto, M.; Camargo, P. B.; Cerri, C. C.; Bernoux, M. Carbono em agregados do solo sob vegetação nativa, pastagem e sistemas agrícolas no Bioma Cerrado. Revista Brasileira de Ciência do Solo, v.36, p.1311-1321, 2012.

EMBRAPA - Empresa Brasileira de Pesquisa Agropecuária. Solos. Manual de métodos de análise de solo. 2. ed. revista. Rio de Janeiro: Embrapa Solos, 2011. 225p.

EMBRAPA - Empresa Brasileira de Pesquisa Agropecuária. Solos. Sistema brasileiro de classificação de solos. . ed. Rio de Janeiro: Embrapa Solos, 2013. 353p.

Ferreira, M. M.; Fernades, B.; Curi, N. Mineralogia da fração argila e estrutura de Latossolos da região sudeste do Brasil. Revista Brasileira de Ciência do Solo, v.23, p.507-514, 1999.

Franco, C. M.; Inforzato, R. O sistema radicular do cafeeiro nos principais tipos de solo do estado de São Paulo. Bragantia, v.6, p.443-478, 1946.

GE Healthcare. Microview analysis 2.2. Technical publication. Direction 2407688. Revision 1. 2006. http://www.oucom. ohiou.edu/ou-microct. 12 Dec. 2011.

Inforzato, R.; Reis, A. J. Estudo comparativo do sistema radicular dos cafeeiros Bourbon amarelo e Mundo Novo. Bragantia, v.22, p.741-750, 1963.

Jesus, A. M. S.; Carvalho, S. P.; Soares, Â. M. Comparação entre sistemas radiculares de mudas de Coffea arabica L. obtidas por estaquia e por sementes. Coffee Science, v.1, p.14-20, 2006.

Jorge, L. A. C.; Silva, D. J. C. B. SAFIRA: Manual de utilização. São Carlos: Embrapa CPDIA, 2010. 29p.

Kaestner, A.; Schneebeli, M.; Graf, F. Visualizing threedimensional root networks using computed tomography. Geoderma, v.136, p.459-469, 2006.

Lima, V. M. P.; Oliveira, G. C.; Serafim, M. E.; Curi, N.; Evangelista, A. R. Intervalo hídrico ótimo como indicador de melhoria da qualidade estrutural de Latossolo degradado. Revista Brasileira de Ciência do Solo, v.36, p.71-78, 2012.

Lynch, J. P. Roots of the second green revolution. Turner Review, Australian Journal of Botany, v.55, p.493-512, 2007.

Mairhofer, S.; Zappala, S.; Tracy, S. R.; Sturrock, C.; Bennett, M.; Mooney, S. J.; Pridmore, T. RooTrak: Automated recovery of three-dimensional plant root architecture in soil from X-ray microcomputed tomography images using visual tracking. Plant Physiology, v.158, p.561-569, 2012.
Martin, S. L.; Mooney, S. J. Dickinson, M. J. West, H. M. The effects of simultaneous root colonisation by three Glomus species on soil pore characteristics. Soil Biology and Biochemistry, v.49, p.167-173, 2012.

Menegasse, L. N.; Gonçalves, J. M.; Fantinel, L. M. Disponibilidades hídricas na Província Cárstica de ArcosPains-Doresópolis. Alto São Francisco. Minas Gerais. Brasil. Revista Águas Subterrâneas, v.16, p.1-19, 2002.

Motta, A. C. V.; Nick, J. A.; Yorinori, G. T.; Serrat, B. M. Distribuição horizontal e vertical da fertilidade do solo e das raízes de cafeeiro (Coffea arabica L.) cultivar Catuaí. Acta Scientiaum Agronomy, v.28, p.455-463, 2006.

R Development Core Team. R: A language and environment for statistical computing. Vienna: R Foundation for statistical computing, 2012. <http://www.R-project.org>. 2 Fev. 2012.

Raij, B. van. Gesso na agricultura. Campinas: Instituto Agronômico, 2008. 233p.

Ramos, B. Z.; Toledo, J. P. V. F.; Lima, J. M.; Serafim, M. E.; Bastos, A. R. R.; Guimarães, P. T. G.; Coscione, A. R. Doses de gesso em cafeeiro: influência nos teores de cálcio. magnésio. potássio e pH na solução de um Latossolo Vermelho Distrófico. Revista Brasileira de Ciência do Solo, v.37, p.1018-1026, 2013.

Rasband, W. ImageJ: Image processing and analysis in Java (Online) 2002. Available at Research Services Branch. National Institute of Health. Bethesda. MD. USA. <http:// rsb.info.nih.gov/ij/index.html>. 10 Nov. 2011.

Rena, A. B.; Guimarães, P. T. G. Sistema radicular do cafeeiro: Estrutura, distribuição, atividade e fatores que o influenciam. Belo Horizonte: EPAMIG, 2000. 80p. Documentos, 37

Ribeiro Júnior, P. J.; Diggle, P. J. GeoR: A package for geoestatistical analysis. R-News, v.1, p.15-18, 2001.

Salton, J. C.; Mielniczuk, J.; Bayer, C.; Boeni, M.; Conceição, P. C.; Fabrício, A. C.; Macedo, M. C. M.; Broch, D. L. Agregação e estabilidade de agregados do solo em sistemas agropecuários em Mato Grosso do Sul. Revista Brasileira de Ciência do Solo, v.32, p.11-21, 2008.

Schaffrath, V. R.; Tormena, C. A.; Fidalski, J.; Andrade, A. C. G. Variabilidade e correlação espacial de propriedades físicas de solo sob plantio direto e preparo convencional. Revista Brasileira de Ciência do Solo, v.32, p.1369-1377, 2008.

Schlüter, S.; Weller, U.; Vogel, H. J. Segmentation of X-ray microtomography images of soil using gradient masks. Computer Geoscience, v.36, p.1246-1251, 2010.

Serafim, M. E.; Oliveira, G. C.; Lima, J. M.; Silva, B.M.; Zeviani, W.M.; Lima, V. M. P. Guimarães, P. T. G.; Costa, J. C. Disponibilidade hídrica e distinção de ambientes para cultivo de cafeeiros. Revista Brasileira de Engenharia Agrícola e Ambiental, v.17, p.362-370, 2013.

Ticianel, T. Sistema mafes (Penta). Empresa Mafes. < http:// www.lpv.esalq.usp.br/lpv584/SISTEMA_MAFES\%20 por\%20Tulio\%20Ticianel.pdf>. 9 Set. 2013.

Vidal-Torrado, P.; Lepsch, I. F.; Castro, S. S.; Cooper, M. Pedogênese em uma seqüência Latossolo podzólico na borda de um platô na depressão periférica paulista. Revista Brasileira de Ciência do Solo, v.23, p.909-921, 1999. 